\title{
The Influence of Aluminum Tripolyphosphate on the Protective Behavior of an Acrylic Water-Based Paint Applied to Rusty Steels
}

\author{
Dongdong Song, Jin Gao, Lin Shen, Hongxia Wan, and Xiaogang Li \\ Corrosion and Protection Center, University of Science and Technology Beijing, Beijing 100083, China \\ Correspondence should be addressed to Jin Gao; gaojin@ustb.edu.cn
}

Received 17 October 2014; Accepted 19 January 2015

Academic Editor: Demeter Tzeli

Copyright (c) 2015 Dongdong Song et al. This is an open access article distributed under the Creative Commons Attribution License, which permits unrestricted use, distribution, and reproduction in any medium, provided the original work is properly cited.

\begin{abstract}
The protective performance, in conditions of total immersion, of an acrylic water-based paint applied to rusty steel, has been studied using electrochemical techniques. There was no rust, blister, crack, or flake that occurred on coating after $500 \mathrm{~h}$ immersion. The data obtained have enabled the protective mechanism to be proposed. The specific pigments utilized in the formulation of the paint studied can release phosphates to form a protective layer on metal substrate, which can impede the access of aggressive species to substrate surface. The coatings performed electrochemical activity in the beginning of immersion; then the layer formed and resistance of coating increased.
\end{abstract}

\section{Introduction}

The corrosion of iron and its alloys gives rise to a yearly loss of billions of dollars. Approximately $90 \%$ of all metallic surfaces are protected with organic coatings [1], on account of their low cost, the ease of application, and their aesthetic functionality. Organic paints are generally made up of binder systems, anticorrosive pigments, fillers, solvents, and various additives $[2,3]$. The anticorrosive ability of coating films rests with metal surface treatment, the type and concentration of anticorrosive pigment, the way of coating formation, and so on [4-8].

Now, government pays more and more attention to personnel healthy and environmental protection. So, composition of paints and their applications are facing more stringent requirements. However, traditional paints are facing adverse condition, because of those utilized volatile organic compounds (VOCs) as solvents and toxic chemical as anticorrosive pigments. Except for a good anticorrosive performance, excellent quality paint shall be equipped with environmental friendliness and easy construction performance. In order to better meet the requirements of industry development, such as aviation and shipbuilding, low VOC, nontoxic, and poor surface preparations are the development direction.
However, due to the environmental and safety issues, considerable research activities have conducted to enhance the increasing demand to reduce volatile organic compounds (VOCs) and hazardous air pollutants emissions, increasing the efforts to formulate waterborne systems for use as coatings [9]. The best known and most frequently applied nontoxic anticorrosive pigments are phosphate pigments. And zinc phosphate was the most important kind of the phosphate pigments before 2004 [10-12]. But the pigments based zinc phosphates were classified according to the European Directive 2004/73/EU as hazardous substances to the environment in 2004 [13]. As result of this fact, the development of "zincfree" inhibitor which is low or zero content of zinc deals with the manufacturers. Aluminum tripolyphosphate is one of the best choices [14-16].

Surface preparation is a key factor prior to painting and the success of the protective coating system depends on its correct execution. Traditional theory believes that poor surface preparation followed by a good coating system usually brings worse results than the use of low quality products on a well prepared surface. Rusts and oxides on the metal surface influence negatively the behavior of a coating system $[17,18]$. The cleaning work is usually very high cost operations and contaminates the environment. A conversion coating can 


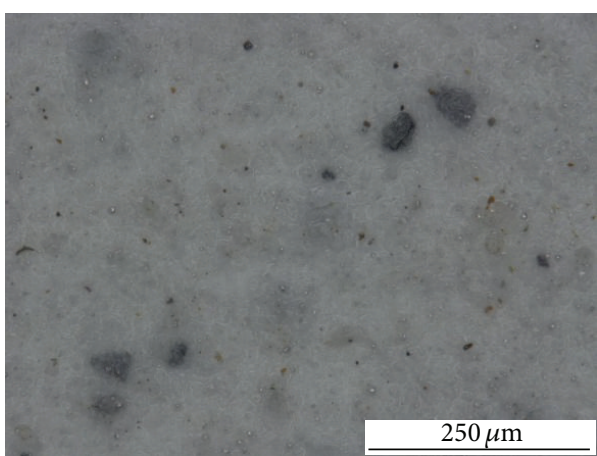

(a)

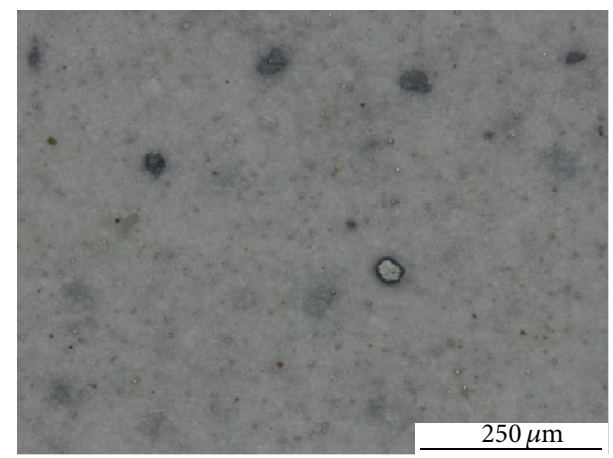

(b)

FIGURE 1: Micrographs of the studied painted samples before and after immersion test. (a) The studied painted samples before immersion. (b) The studied painted samples after immersion.

meet the challenge. It may be defined as one formed by a chemical reaction which converts the surface of a metal substrate into a compound which became part of the coating.

Now, our team has excogitated a new paint that employs noncontaminating inhibitors, water as solvent, and can meet poor surface preparation. In order to better demonstrate the protective function of coating, the behavior of this acrylic water-based paint applied to rusty steel is studied by electrochemical techniques.

\section{Experimental}

2.1. Samples. The behavior of a new acrylic paint produced by our lab has been studied. Table 1 gives the more important technical characteristics of this paint. Mild steel, Q235, has been employed as the metallic substratum. The samples studied were rectangular test pieces of $100 \mathrm{~mm} \times 150 \mathrm{~mm} \times$ $1 \mathrm{~mm}$. The samples were abraded using $\mathrm{SiC}$ abrasive papers up to 240 grit, washed in distilled water and acetone in turn, and then dried in air. After that, samples sprayed a solution of $3.5 \% \mathrm{NaCl}$ for 15 days to be rusting. Before painting, floating rust of sample was cleaned by $\mathrm{SiC}$ abrasive papers. The paint was then applied using a brush to a thickness of $130 \mu \mathrm{m}$ and the compared samples of epoxy antirust paint were $160 \mu \mathrm{m}$. The shapes of scratches were $X$ for EIS and line for LEIS. All scratches were made by utility knife for $10 \mathrm{~mm}$ long and $50 \mu \mathrm{m}$ wide. The distance between scratch and each edge of samples was more than $20 \mathrm{~mm}$.

2.2. Electrochemical Measurements. EIS measurements were carried out in the solution of $3.5 \mathrm{wt} \% \mathrm{NaCl}$ with a PARSTAT 2273 system, over the frequency range from $10^{5} \mathrm{~Hz}$ to $10^{-2} \mathrm{~Hz}$ at open circuit potential, with a $20 \mathrm{mV}$ potential perturbation. The internal parallel capacitance of the measuring machine was smaller than $5 \mathrm{pF}$. A three-electrode arrangement was used, consisting of a saturated calomel electrode (SCE) as reference electrode, a platinum electrode as counter electrode, and the coated sample as the working electrode. For the working electrode the exposing area was $3.14 \mathrm{~cm}^{2}$, which would decrease the magnitude of the measured impedance and avoid hitting the limit of the measurement instrumentation,
TABLE 1: Technical sheet of studied paint from our lab.

\begin{tabular}{ll}
\hline Product description & Water-based acrylic primer \\
Intended uses & $\begin{array}{l}\text { For use at new steel structure and } \\
\text { maintenance and repair }\end{array}$ \\
Color & Gray \\
Volume solids & $61 \pm 2 \%$ (ISO 3233:1998) \\
Typical film thickness & $100 \mu \mathrm{m}$ dry \\
Method of application & Airless spray, brush, roller \\
\hline
\end{tabular}

especially at moderate and high frequencies. The Pt electrode area was nearly the size of the working electrode, about $4 \mathrm{~cm}^{2}$. Fitting of the impedance spectra was made using ZsimpWin software.

The LEIS measurements were performed on coating specimens that immersed in $3.5 \% \mathrm{NaCl}$ solution through a PAR Model 370 Scanning Electrochemical Workstation. Thus, the test solution for LEIS measurements was $0.001 \mathrm{M} \mathrm{NaCl}$ solution. The microprobe was stepped over a designated area of the electrode surface. The scanning took the form of a raster in $x-y$ plane. The step size was controlled to obtain a plot of 32 lines $\times 21$ lines. The AC disturbance signal was $100 \mathrm{mV}$, and the excitation frequency for impedance measurements was fixed at $5 \mathrm{kHz}$. All LEIS measurements were carried out at ambient temperature $\left(\sim 22^{\circ} \mathrm{C}\right)$. Each test was performed at least twice to confirm the repeatability.

\section{Results and Discussion}

3.1. Immersion Tests. Figure 1 shows the corrosion microtopography of a painted sample, immersed in the solution of $3.5 \mathrm{wt} \% \mathrm{NaCl}$ for 21 days. As can be observed, there was no rust, blister, crack, or flake that occurred on coating, which indicates that the coating has remarkable corrosion resistance performance.

In Table 2, the comparison of the corrosion morphology between epoxy antirust paint and our paint in function of the time of exposure is represented. The result shows that the studied coating achieved a good anticorrosive performance. After 24 hours exposure, there was obvious rusting in scratch 
TABLE 2: Immersion testing results for scratched coating samples after different stage.

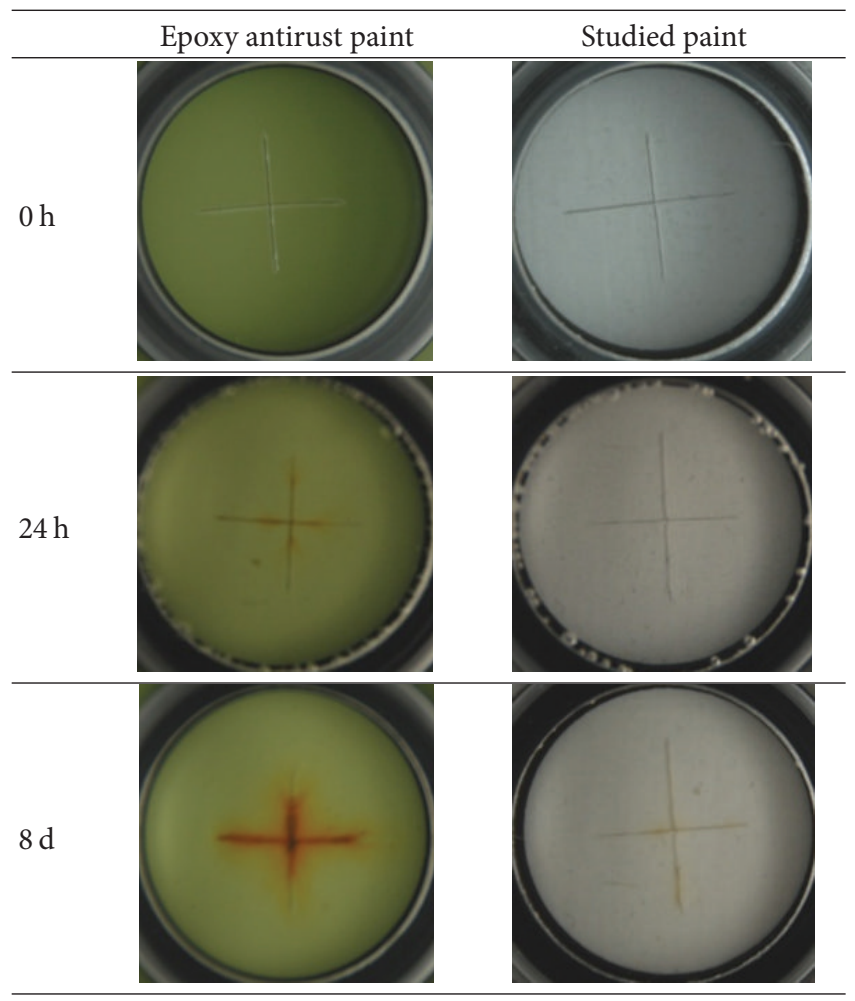

of epoxy antirust coating but no change in the studied coating. The scratch of the studied coating still did not have apparent rust in 8 days exposure; however, serious corrosion was found in epoxy antirust coating sample and even blister.

From the above results, the studied coating shows the function of inhibition to $3.5 \% \mathrm{NaCl}$ solution after immersion. Particularly, compared to epoxy antirust coating, it is easy to see that the studied coating is provided with self-healing ability. This will be discussed in detail in the following sections.

\subsection{Electrochemical Impedance Spectroscopy. Figure 2 shows} the EIS diagrams corresponding to tests made on painted samples after being subjected to tests of different periods of duration. The data obtained demonstrate that, in the first $12 \mathrm{~h}$ of immersion, interesting changes have taken place. The Nyquist diagrams of the system in $1 \mathrm{~h}$ consisted of half a capacitive reactance arc of high frequency and a low frequency of capacitive reactance arc. After $2 \mathrm{~h}$, those turned into a single capacitive arch. There was a considerable decrease of the arch that appeared in the Nyquist diagrams of first $2 \mathrm{~h}$ and increase after $4 \mathrm{~h}$. In parallel, a decrease was observed in the modulus of the impedance in the Bode diagrams of first $2 \mathrm{~h}$ and increase after $4 \mathrm{~h}$. This decrease in the impedance suggests that, during the first hours of immersion, there is an increase in the activity taking place in the system in this period. Figure 2(b) shows that the Nyquist diagrams present a single capacitive arch and the arch increases continuously from $1 \mathrm{~d}$ to $21 \mathrm{~d}$.
Figure 3 shows the EIS diagrams corresponding to tests made on samples of studied paint with scratch after being subjected to tests of different periods of duration. The Nyquist diagrams presented a single capacitive arch. Being parallel to intact painted samples, there was a considerable decrease of the arch that appeared in the Nyquist diagrams first and increased then. By contrast, the Nyquist diagrams of epoxy antirust coatings with scratch (Figure 4) presented a single capacitive arch too, but it decreased over time. It is easy to see that the modulus of the samples of studied coating with scratch in the Bode diagrams was inferior to that of epoxy antirust paint in initiation. But after 8 days of immersion, inversion has happened. Figure 5 shows the phenomenon obviously. It is in accordance with the result of immersion

$$
\begin{gathered}
\mathrm{AlH}_{2} \mathrm{P}_{3} \mathrm{O}_{10} \longrightarrow \mathrm{Al}^{3+}+2 \mathrm{H}^{+}+\mathrm{P}_{3} \mathrm{O}_{10}{ }^{5-} \\
\mathrm{Fe}^{2+}+\mathrm{Fe}^{3+}+\mathrm{P}_{3} \mathrm{O}_{10}{ }^{5-} \longrightarrow \mathrm{Fe}_{2} \mathrm{P}_{3} \mathrm{O}_{10} \\
\mathrm{P}_{3} \mathrm{O}_{10}{ }^{5-}+2 \mathrm{H}_{2} \mathrm{O} \longrightarrow 3 \mathrm{PO}_{4}{ }^{3-}+4 \mathrm{H}^{+} \\
x\left(\mathrm{Fe}^{2+}, \mathrm{Fe}^{3+}\right)+y \mathrm{PO}_{4}{ }^{3-} \longrightarrow \mathrm{Fe}_{x}\left(\mathrm{PO}_{4}\right)_{y}
\end{gathered}
$$

In order to guarantee the poor surface preparation and a good anticorrosive performance of our paint, many specific pigments are added in it. These specific pigments are chemical active, so the modulus of coating is at a low level. The specific pigment utilized in the formulation of the studied coating is aluminum triphosphate. The mechanism of actuation of this compound has not been clearly established.

In last decades, phosphate-based pigments are frequently applied in coatings to improve their corrosion resistance [1922]. When the water has penetrated into the coating, the pigments based on phosphate anions can release phosphates to form a protective layer on the metal substrate, which can impede the access of the aggressive species to the substrate surface [22, 23]. Particularly, aluminum tripolyphosphate could hydrolyze to produce $\mathrm{H}^{+}$, which could minimize the hydroxyl production on the metal substrate and retard cathode disbanding to prolong the service life of organic coatings [14].

At $1 \mathrm{~h}$, the Nyquist diagrams of the system consisted of one half of capacitive arc at high frequencies and another half of capacitive arc at low frequencies. The one at high frequencies can be attributed to the reaction between water and the large amount of aluminum triphosphate well dispersed in the coating matrix. The equivalent circuit shown in Figure 6(a) has been selected to simulate the data of $1 \mathrm{~h}$. After $2 \mathrm{~h}$ of immersion, as aluminum triphosphate continues to react with water, denser protective layer was formed, which seal the conduits for water penetration and lead to an increase in barrier property of the coating. As a result, the Bode diagram of the system demonstrated only a single time constant, as shown in Figure 2. For this reason, the equivalent circuit of Figure 6(c) has been selected. In the circuit, $R_{s}$ represents the resistance between the working electrode and the reference electrode, generally associated with the ohm resistance of the electrolyte. $C_{\mathrm{dl}}$ and $R_{t}$ are related to double-layer capacitance and charge-transfer resistance of the chemically active pigments, 


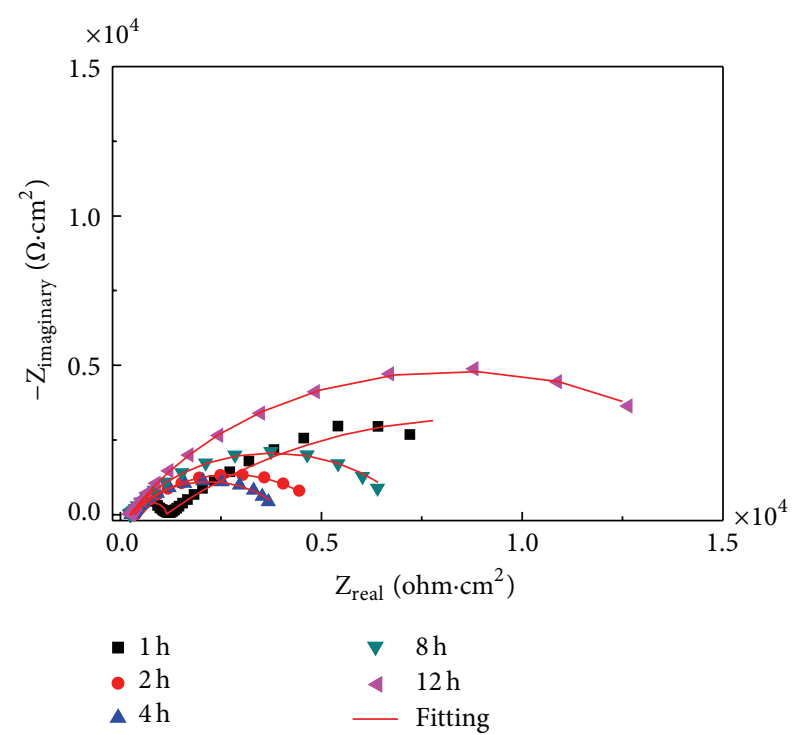

(a)

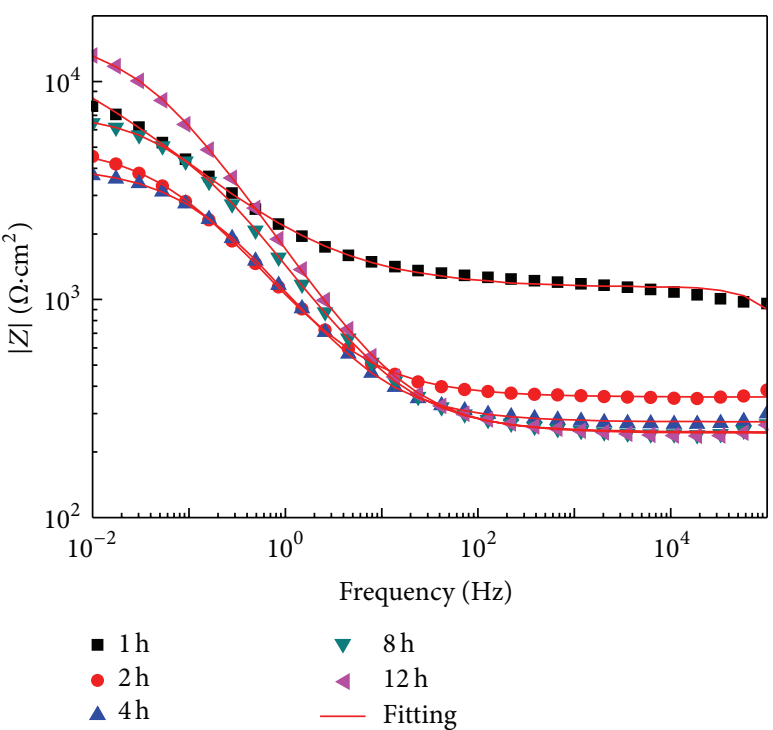

(c)

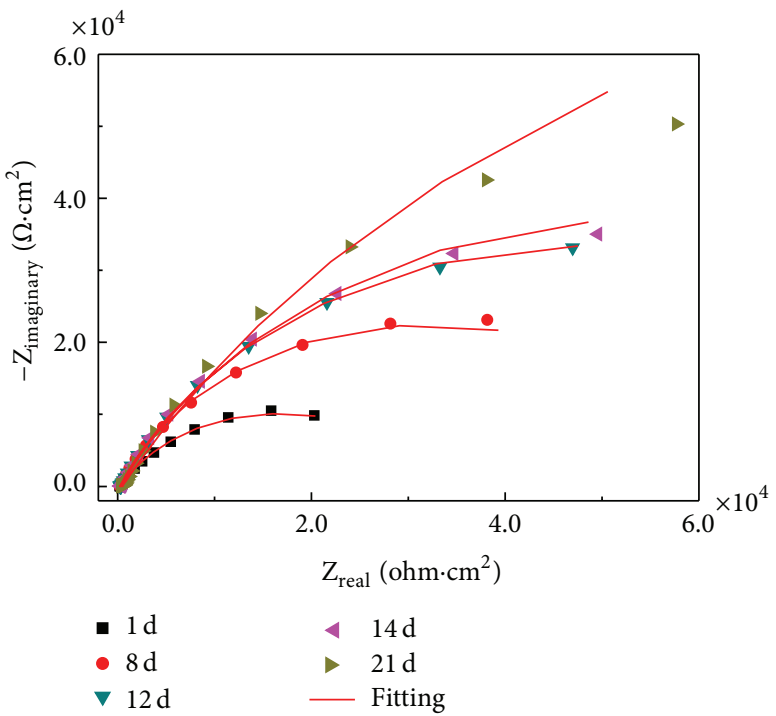

(b)

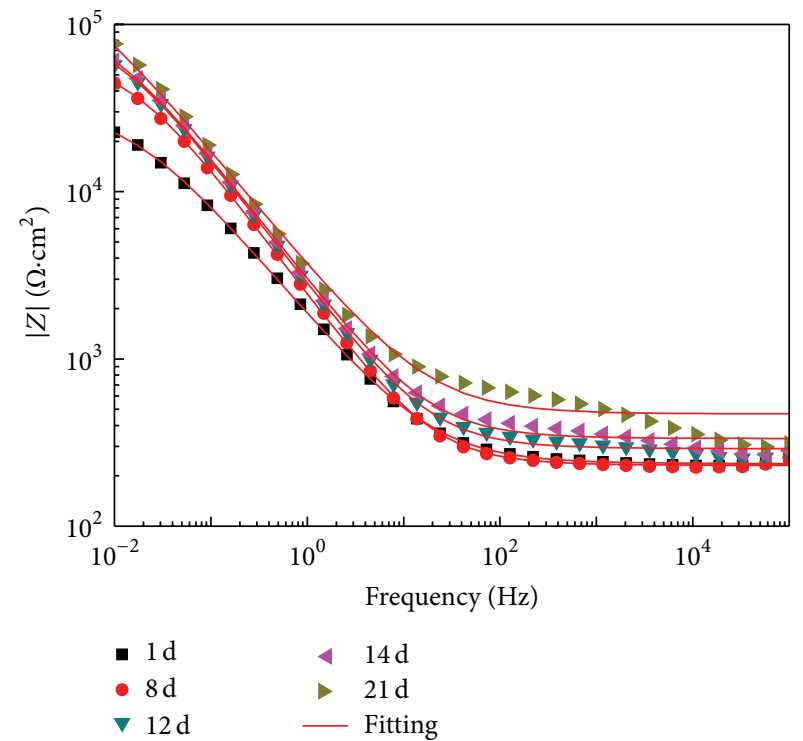

(d)

FIGURE 2: Impedance spectra of painted samples without scratch after different immersion time in 3.5 wt\% NaCl solution: (a) Nyquist plots from $1 \mathrm{~h}$ to $12 \mathrm{~h}$, (b) Nyquist plots from $1 \mathrm{~d}$ to $21 \mathrm{~d}$, (c) Bode plots from $1 \mathrm{~h}$ to $12 \mathrm{~h}$, and (d) Bode plots from $1 \mathrm{~d}$ to $21 \mathrm{~d}$.

respectively. $Q_{c}$ is related to the capacitance of the coating. $R_{c}$ is the resistance of the pores and is a measure of the porosity as a consequence of the degradation of the coating.

Study of the evolution of the diagrams of EIS with time of immersion enables an analysis to be made about the variation of the protective capacity of painted samples. In our case, from the fit of the experimental diagrams to the equivalent circuit proposed, the values of the capacity, $Q_{c}$, and of the resistance, $R_{c}$, associated with the layer of paint, have been calculated (Table 3). Figure 7 presents the evolution of these parameters during the first $24 \mathrm{~h}$ of exposure. In this figure, it can be observed how, as the time of exposure is increased, the resistance of the coating decreased first and then increased. It is due to the anticorrosive performance of aluminum tripolyphosphate that the number of defects in the coating decreases as protective layer forms. In the first $2 \mathrm{~h}$ of exposure, the capacity of coating increased, because the water penetrates into the coating and the conductivity of the coating increases. However, aluminum triphosphate releases phosphates to form a protective layer on the metal substrate to impede the access of the aggressive species and corrosion. So the conductivity is reduced and capacity is down.

Figure 3 shows the EIS diagrams of our painted samples with scratch after being subjected to tests of different periods of duration. The Nyquist diagrams present a single capacitive loop all the time. There is a considerable decrease of the arch that appears in the Nyquist diagrams first and increases then. Reason for this phenomenon is that aluminum triphosphate 


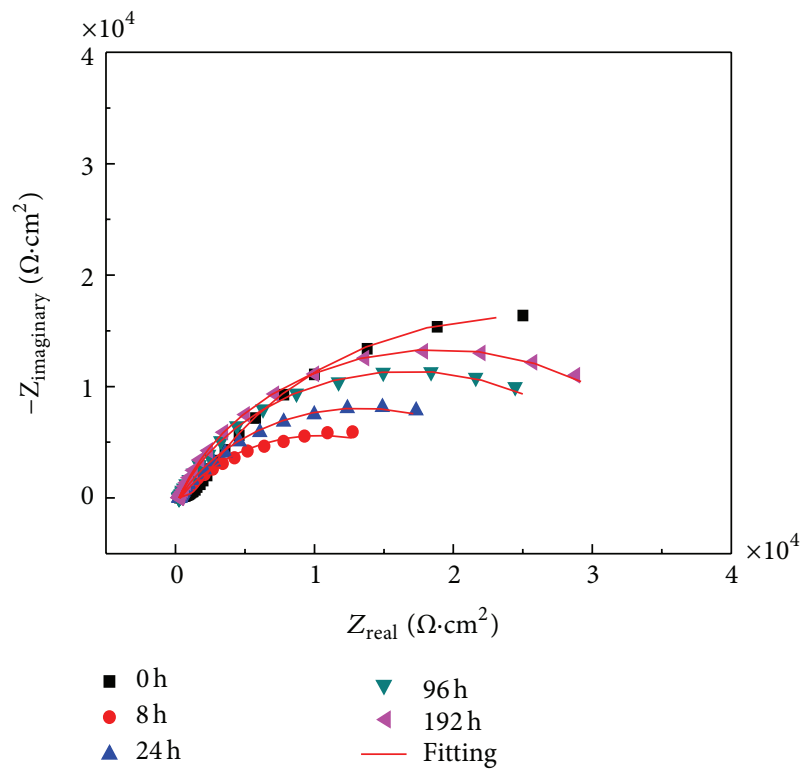

(a)

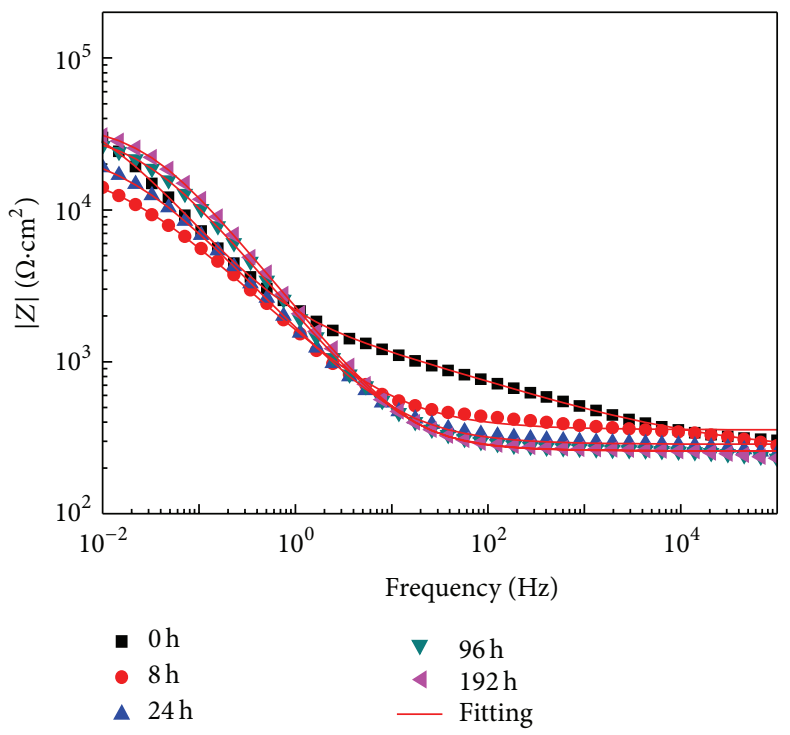

(b)

FiguRE 3: Impedance spectra of painted samples with scratch after different immersion time in $3.5 \mathrm{wt} \% \mathrm{NaCl}$ solution: (a) Nyquist plots and (b) Bode plots.

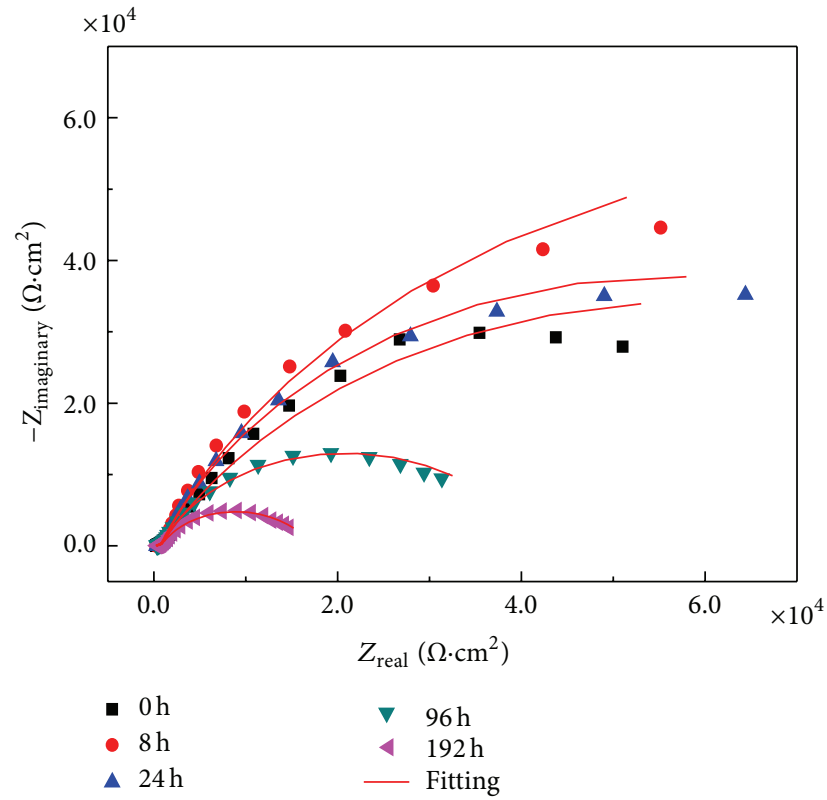

(a)

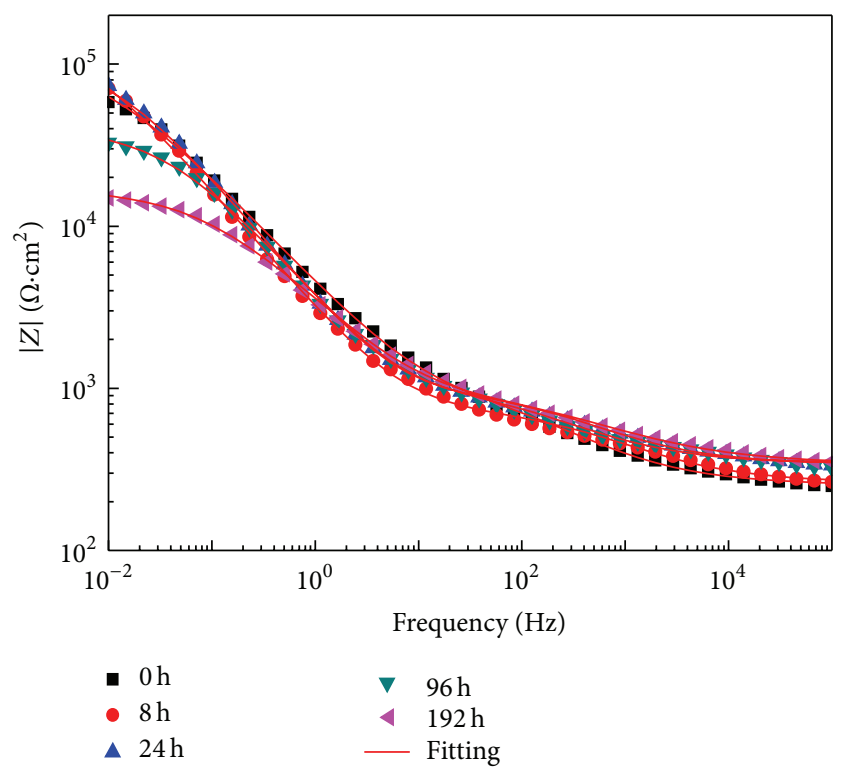

(b)

FIGURE 4: Impedance spectra of epoxy antirust painted samples with scratch after different immersion time in $3.5 \mathrm{wt} \% \mathrm{NaCl}$ solution: (a) Nyquist plots and (b) Bode plots.

TABLE 3: Impedance value of painted samples without scratch calculated from EIS spectra.

\begin{tabular}{lcccccc}
\hline & $1 \mathrm{~h}$ & $2 \mathrm{~h}$ & $4 \mathrm{~h}$ & $8 \mathrm{~h}$ & $12 \mathrm{~h}$ & $1 \mathrm{~d}$ \\
\hline$R_{s}\left(\Omega \cdot \mathrm{cm}^{2}\right)$ & 274.6 & 357.6 & 274.9 & 246.9 & 244.2 \\
$Y_{0}$ of $Q_{c}\left(\mathrm{~F} \cdot \mathrm{cm}^{-2} \cdot \mathrm{s}^{n-1}\right)$ & $3.26 \times 10^{-4}$ & $3.43 \times 10^{-4}$ & $2.85 \times 10^{-4}$ & $2.05 \times 10^{-4}$ & $1.73 \times 10^{-4}$ & $1.53 \times 10^{-4}$ \\
$n$ & 0.4926 & 0.6544 & 0.6686 & 0.6743 & 0.6837 \\
$R_{c}\left(\Omega \cdot \mathrm{cm}^{2}\right)$ & $1.58 \times 10^{4}$ & 4776 & 3818 & 7051 & $1.61 \times 10^{4}$ & $3.29 \times 10^{4}$ \\
\hline
\end{tabular}




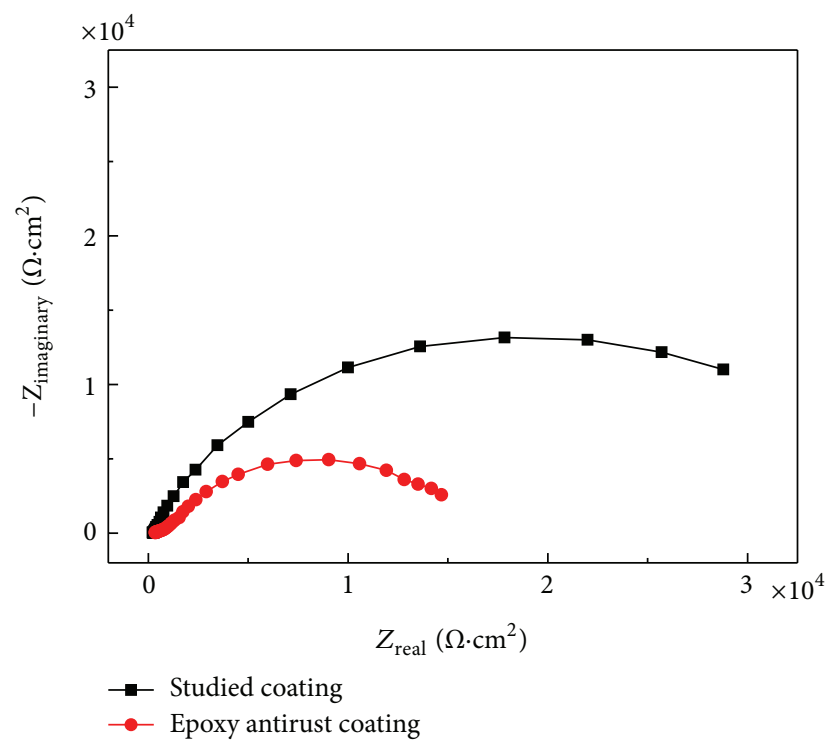

FIGURE 5: Impedance spectra of epoxy antirust painted samples and painted samples with scratch after 8-day immersion times in 3.5 wt $\%$ $\mathrm{NaCl}$ solution.

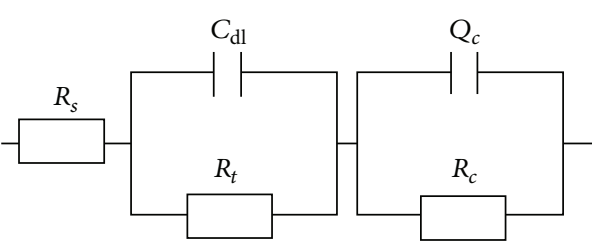

(a)

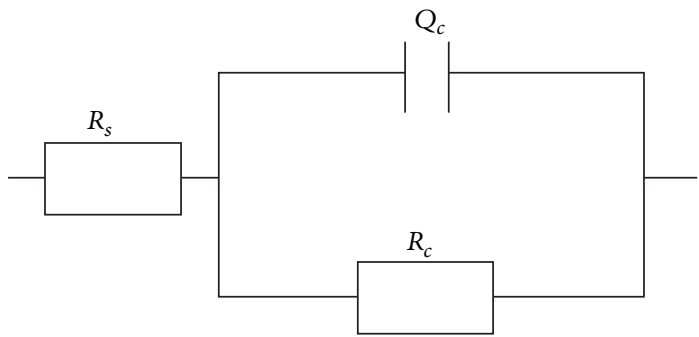

(c)

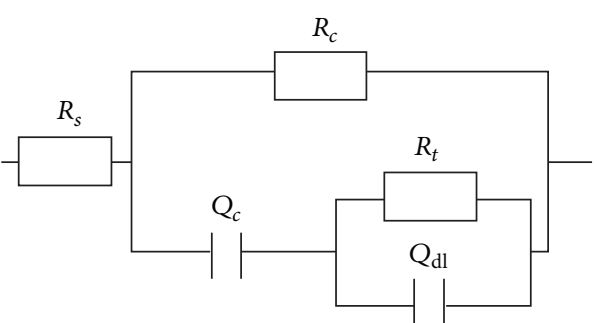

(b)

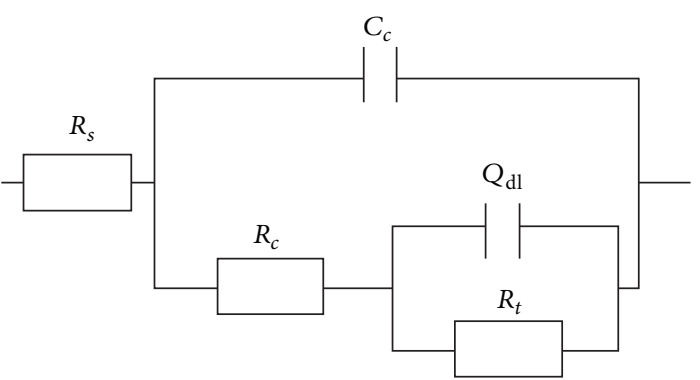

(d)

FIGURE 6: Equivalent circuit representing the coating system.

releases phosphates to form a protective layer on the metal substrate as the water enters from the defect. In the beginning, the reactions cause the decrease of arch of the Nyquist diagrams and select the equivalent circuit of Figure 6(b). Along with immersion extension, the protective layer becomes compact and the arch increases. For this reason, the equivalent circuit of Figure 6(c) is selected (Table 4). There is a considerable increase of the capacity of the coating first and then decrease. Meanwhile, the resistance of the coating behaves on the contrary (Figure 8).

For the epoxy antirust painted samples with scratch, the Nyquist diagrams present a single capacitive arch too
(Figure 4). But plots from Bode diagrams show two time constants and the low frequency impedance was reduced as time extends, because the water and aggressive ions diffuse on the substrate/coating interface. So the equivalent circuit of Figure 6(d) is selected (Table 5).

3.3. Localised Electrochemical Impedance Mapping. As indicated in the LEIS projection of epoxy antirust coating (Figure 9), in initial stage of immersion, the impedance value at the defect was much lower than that of the adjacent intact coating because of corrosion of bare metal in defect. When 


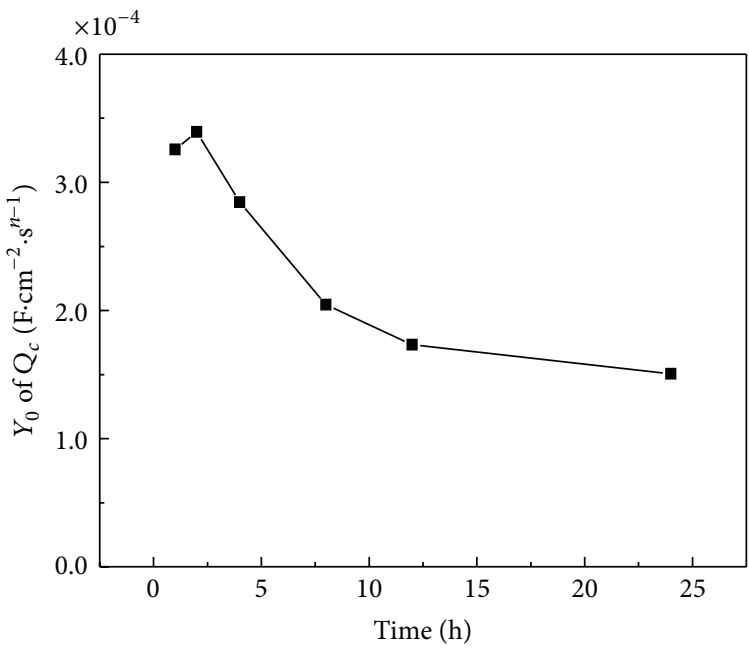

(a)

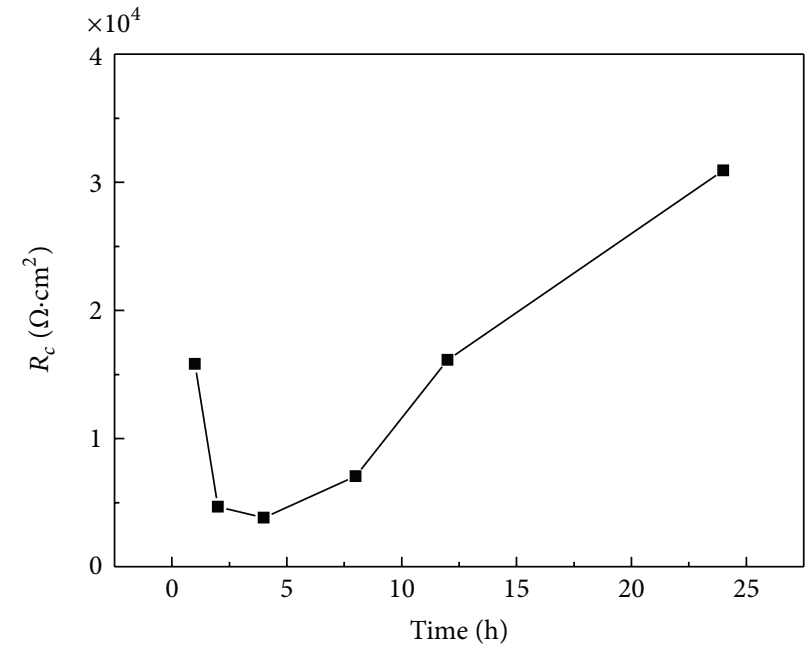

(b)

FIgURE 7: Time evolution of $Q_{c}$ and $R_{c}$ of painted samples without scratch values calculated from EIS spectra.

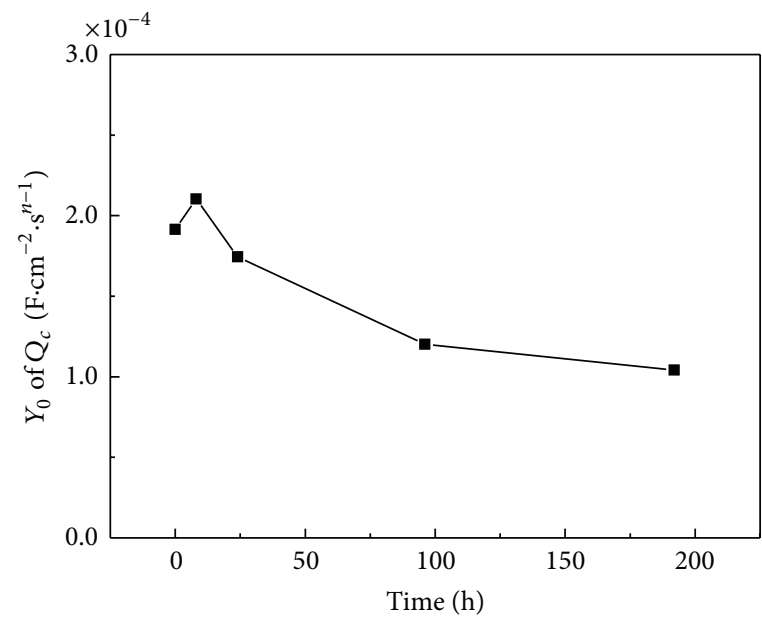

(a)

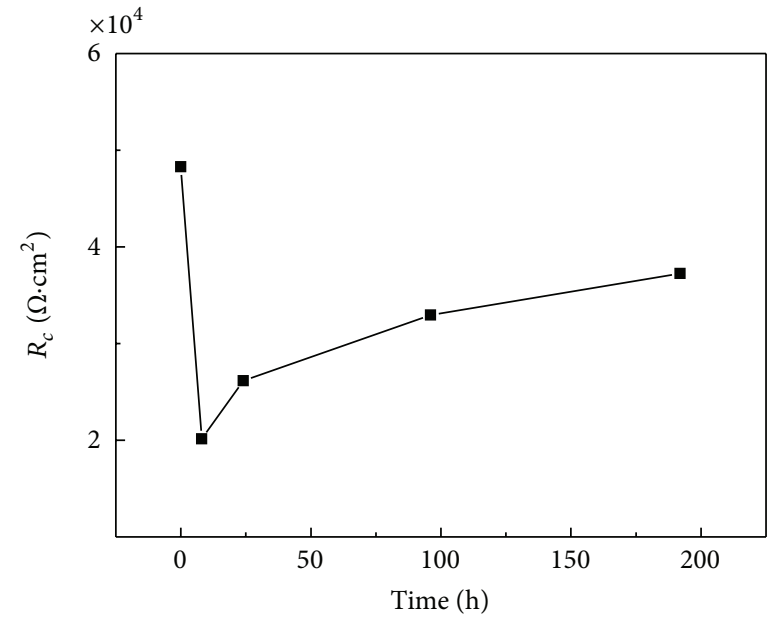

(b)

FIGURE 8: Time evolution of $Q_{c}$ and $R_{c}$ of painted samples with scratch values calculated from EIS spectra.

TABLE 4: Impedance value of painted samples with scratch calculated from EIS spectra.

\begin{tabular}{lccccc}
\hline & $0 \mathrm{~h}$ & $8 \mathrm{~h}$ & $24 \mathrm{~h}$ & $96 \mathrm{~h}$ & $192 \mathrm{~h}$ \\
\hline$R_{s}\left(\Omega \cdot \mathrm{cm}^{2}\right)$ & 243.5 & 356.7 & 286.4 & 258.9 & 259 \\
$Y_{0}$ of $Q_{c}\left(\mathrm{~F} \cdot \mathrm{cm}^{-2} \cdot \mathrm{s}^{n-1}\right)$ & $1.91 \times 10^{-4}$ & $2.10 \times 10^{-4}$ & $1.75 \times 10^{-4}$ & $1.20 \times 10^{-4}$ & $1.04 \times 10^{-4}$ \\
$n$ & 0.7724 & 0.6473 & 0.7035 & 0.7698 & 0.7913 \\
$R_{c}\left(\Omega \cdot \mathrm{cm}^{2}\right)$ & $4.83 \times 10^{4}$ & $2.02 \times 10^{4}$ & $2.62 \times 10^{4}$ & $3.30 \times 10^{4}$ & $3.73 \times 10^{4}$ \\
\hline
\end{tabular}

TABLE 5: Impedance value of epoxy antirust painted samples with scratch calculated from EIS spectra.

\begin{tabular}{lccccc}
\hline & $0 \mathrm{~h}$ & $8 \mathrm{~h}$ & $24 \mathrm{~h}$ & $96 \mathrm{~h}$ & $192 \mathrm{~h}$ \\
\hline$R_{s}\left(\Omega \cdot \mathrm{cm}^{2}\right)$ & 278.2 & 296.4 & 380.1 & 382.9 & 341.3 \\
$C_{c}\left(\mathrm{~F} \cdot \mathrm{cm}^{-2}\right)$ & $5.92 \times 10^{-7}$ & $4.09 \times 10^{-7}$ & $6.32 \times 10^{-7}$ & $9.90 \times 10^{-7}$ & $3.83 \times 10^{-7}$ \\
$R_{c}\left(\Omega \cdot \mathrm{cm}^{2}\right)$ & 277.8 & 283.1 & 358.8 & 333.9 & 267.4 \\
$Y_{0}$ of $Q_{\mathrm{dl}}\left(\mathrm{F} \cdot \mathrm{cm}^{-2} \cdot \mathrm{s}^{n-1}\right)$ & $6.52 \times 10^{-5}$ & $8.35 \times 10^{-5}$ & $6.986 \times 10^{-5}$ & $7.17 \times 10^{-5}$ & $8.56 \times 10^{-5}$ \\
$n$ & 0.65 & 0.7302 & 0.7465 & 0.7209 & 0.6377 \\
$R_{t}\left(\Omega \cdot \mathrm{cm}^{2}\right)$ & $1.35 \times 10^{5}$ & $1.83 \times 10^{5}$ & $1.163 \times 10^{5}$ & $4.1 \times 10^{4}$ & $1.74 \times 10^{4}$ \\
\hline
\end{tabular}



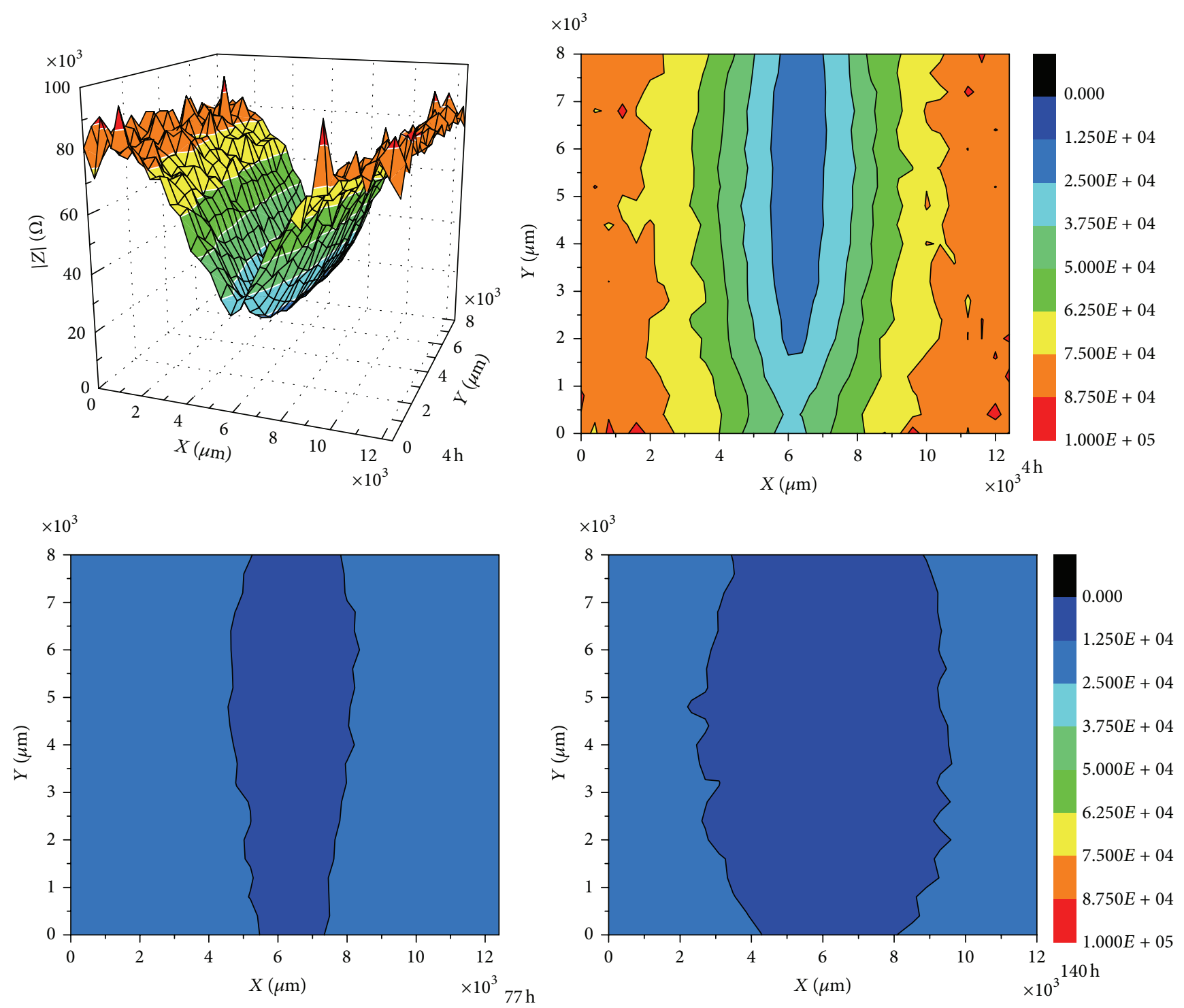

FIGURE 9: Time dependence of LEIS profiles and their projections of epoxy antirust painted samples.

the immersion time extended, the impedance in the adjacent coating decreases, which is attributed to permeation of corrosive solution from the defect and the resultant disbanding of coating, as observed visually after test, and there are many blisters around the defect (Figure 11).

The present work (Figure 10) shows that, in contrast to the impedance results measured on epoxy antirust coating, the impedance value at the defect was not lower than that of the adjacent intact coating of studied coating sample all of the immersion time. Corresponding to results of electrochemical impedance spectroscopy, the impedance value of studied coating increased over time, because the pigments based on phosphate anions can release phosphates to form a protective layer on the metal substrate, which can impede the access of the aggressive species to the substrate surface. The results of LEIS show that the studied coatings presented better selfhealing and anticorrosive feature.

\section{Conclusions}

The behavior, in conditions of total immersion, of an acrylic water-based paint applied to rusty steel, has been studied using electrochemical techniques. The set of data obtained has enabled a mechanism for the anticorrosive performance of the coating.

This coating had a good anticorrosive performance. After 21 days of total immersion, there was no rust, blister, crack, or flake that occurred on coating. Compared to the epoxy antirust painted samples, the studied coatings exhibited better self-healing and anticorrosive feature. The electrochemical results show that the specific pigments utilized in the formulation of the paint studied caused the electrochemical activity of the coating. When the water has penetrated into the coating, the pigments based on phosphate anions can release phosphates to form a protective layer on the metal substrate. 

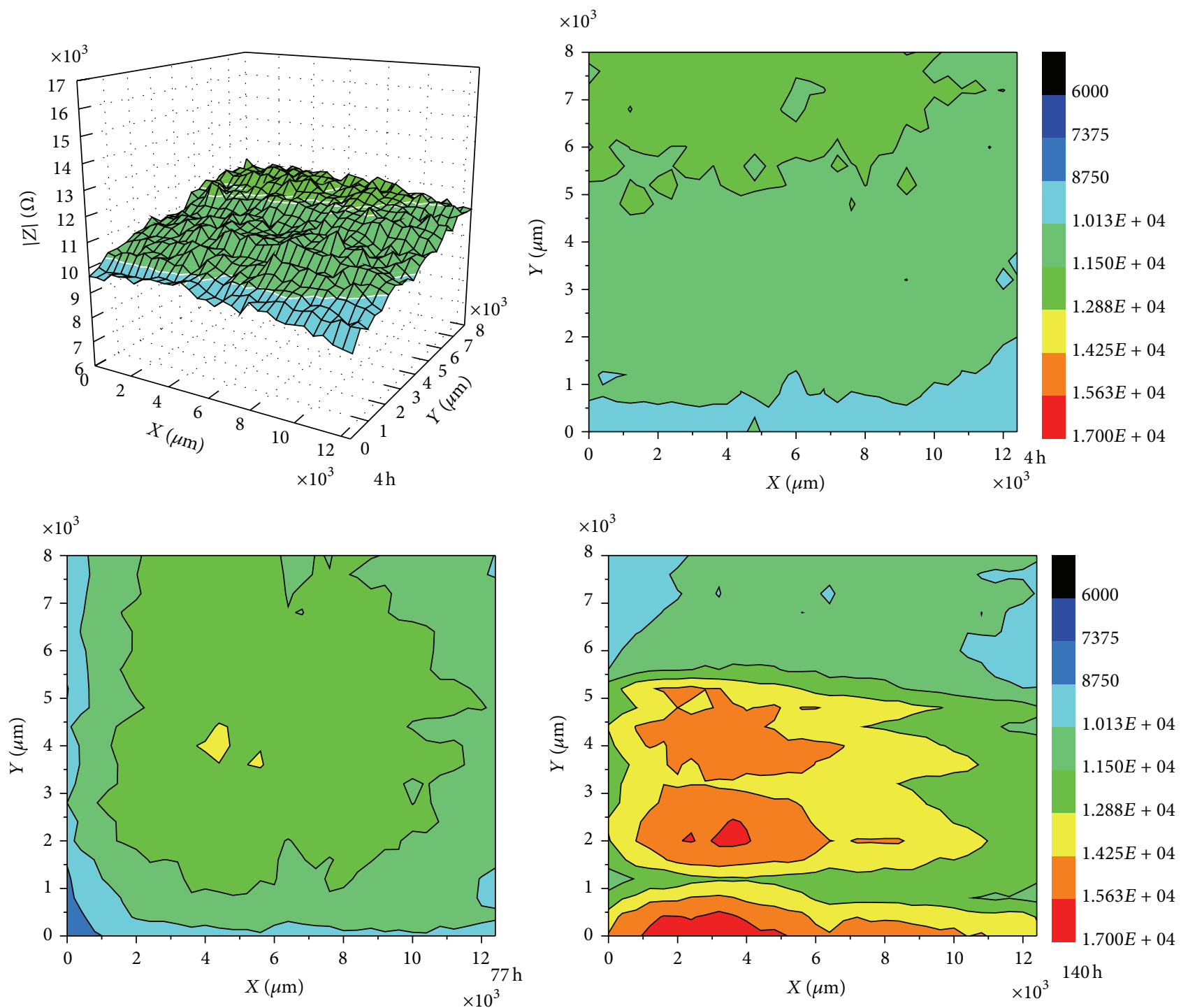

FIGURE 10: Time dependence of LEIS profiles and their projections of studied painted samples.

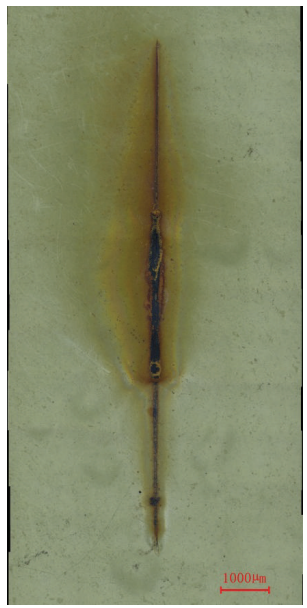

(a)

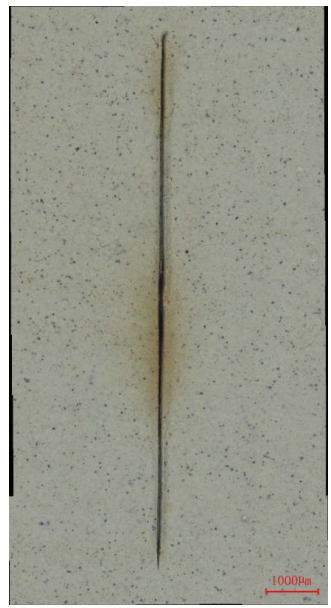

(b)

FIgURE 11: Micrographs of the epoxy antirust painted samples (a) and studied painted samples (b) with defect after immersion test. 
The layer prevents the access of water and corrosion reaction to protect substrate.

\section{Conflict of Interests}

The authors declare that there is no conflict of interests regarding the publication of this paper.

\section{Acknowledgment}

The authors wish to acknowledge the financial support of the National Natural Science Foundation of China (no. 51071027).

\section{References}

[1] K. Barton, Protection against Atmospheric Corrosion, John Wiley \& Sons, New York, NY, USA, 1976.

[2] D. El-Hamid, G. Blustein, M. Deyá, B. del Amo, and R. Romagnoli, "The anticorrosive performance of zinc-free non-toxic pigment for paints," Materials Chemistry and Physics, vol. 127, no. 1-2, pp. 353-357, 2011.

[3] E. Armelin, M. Martí, F. Liesa, J. I. Iribarren, and C. Alemán, "Partial replacement of metallic zinc dust in heavy duty protective coatings by conducting polymer," Progress in Organic Coatings, vol. 69, no. 1, pp. 26-30, 2010.

[4] D. Veselý, A. Kalendová, and P. Němec, "Properties of organic coatings depending on chemical composition and structure of pigment particles," Surface and Coatings Technology, vol. 204, no. 12-13, pp. 2032-2037, 2010.

[5] J. Havlík, A. Kalendová, and D. Veselý, "Electrochemical, chemical and barrier action of zinc dust/anticorrosive pigments containing coatings," Journal of Physics and Chemistry of Solids, vol. 68, no. 5-6, pp. 1101-1105, 2007.

[6] M. Zubielewicz, E. Kamińska-Tarnawska, and A. Kozłowska, "Protective properties of organic phosphate-pigmented coatings on phosphated steel substrates," Progress in Organic Coatings, vol. 53, no. 4, pp. 276-285, 2005.

[7] P. Mošner, A. Kalendová, and L. Koudelka, "The effects of the mode of preparation on the anticorrosion properties of $\mathrm{Ca}-\mathrm{Zn}$ and Mg-Zn borophosphates," Pigment \& Resin Technology, vol. 32, no. 3, pp. 166-174, 2003.

[8] A. Kalendová, D. Veselý, and P. Kalenda, "Anticorrosion pigment based on calcium titanate with a perovskite structure," Pigment and Resin Technology, vol. 36, no. 3, pp. 123-133, 2007.

[9] J.-M. Yeh, C.-T. Yao, C.-F. Hsieh et al., "Preparation, characterization and electrochemical corrosion studies on environmentally friendly waterborne polyurethane $/ \mathrm{Na}^{+}-\mathrm{MMT}$ clay nanocomposite coatings," European Polymer Journal, vol. 44, no. 10, pp. 3046-3056, 2008.

[10] A. Kalendová and J. Brodinová, "Spinel and rutile pigments containing $\mathrm{Mg}, \mathrm{Ca}, \mathrm{Zn}$ and other cations for anticorrosive coatings," Anti-Corrosion Methods and Materials, vol. 50, no. 5, pp. 352-363, 2003.

[11] M. Bethencourt, F. J. Botana, M. Marcos, R. M. Osuna, and J. M. Sánchez-Amaya, "Inhibitor properties of 'green' pigments for paints," Progress in Organic Coatings, vol. 46, no. 4, pp. 280-287, 2003.

[12] M. C. Deyá, G. Blustein, R. Romagnoli, and B. del Amo, "The influence of the anion type on the anticorrosive behaviour of inorganic phosphates," Surface and Coatings Technology, vol. 150, no. 2-3, pp. 133-142, 2002.

[13] H. Kukackova, A. Vraštilová, and A. Kalendova, "Non-toxic anticorrosive pigments intended for applications in high-solids and waterborne paints," Physics Procedia, vol. 44, pp. 238-246, 2013.

[14] X. Lu, Y. Zuo, X. Zhao, and Y. Tang, "The influence of aluminum tri-polyphosphate on the protective behavior of Mg-rich epoxy coating on AZ91D magnesium alloy," Electrochimica Acta, vol. 93, pp. 53-64, 2013.

[15] S. N. Roselli, B. del Amo, R. O. Carbonari, A. R. Di Sarli, and R. Romagnoli, "Painting rusted steel: the role of aluminum phosphosilicate," Corrosion Science, vol. 74, pp. 194-205, 2013.

[16] M. Deyá, V. F. Vetere, R. Romagnoli, and B. del Amo, "Aluminium tripolyphosphate pigments for anticorrosive paints," Pigment \& Resin Technology, vol. 30, no. 1, pp. 13-24, 2001.

[17] D. de la Fuente, J. Simancas, and M. Morcillo, "Effect of variable amounts of rust at the steel/paint interface on the behaviour of anticorrosive paint systems," Progress in Organic Coatings, vol. 46, no. 4, pp. 241-249, 2003.

[18] C. I. Elsner, E. Cavalcanti, O. Ferraz, and A. R. Di Sarli, "Evaluation of the surface treatment effect on the anticorrosive performance of paint systems on steel," Progress in Organic Coatings, vol. 48, no. 1, pp. 50-62, 2003.

[19] P. de Lima-Neto, A. P. de Araújo, W. S. Araújo, and A. N. Correia, "Study of the anticorrosive behaviour of epoxy binders containing non-toxic inorganic corrosion inhibitor pigments," Progress in Organic Coatings, vol. 62, no. 3, pp. 344-350, 2008.

[20] R. Naderi and M. M. Attar, "Electrochemical study of protective behavior of organic coating pigmented with zinc aluminum polyphosphate as a modified zinc phosphate at different pigment volume concentrations," Progress in Organic Coatings, vol. 66, no. 3, pp. 314-320, 2009.

[21] C. Deyá, G. Blustein, B. Del Amo, and R. Romagnoli, "Evaluation of eco-friendly anticorrosive pigments for paints in service conditions," Progress in Organic Coatings, vol. 69, no. 1, pp. 1-6, 2010.

[22] R. Naderi and M. M. Attar, "The role of zinc aluminum phosphate anticorrosive pigment in Protective Performance and cathodic disbondment of epoxy coating," Corrosion Science, vol. 52, no. 4, pp. 1291-1296, 2010.

[23] M. A. Hernández, F. Galliano, and D. Landolt, "Mechanism of cathodic delamination control of zinc-aluminum phosphate pigment in waterborne coatings," Corrosion Science, vol. 46, no. 9, pp. 2281-2300, 2004. 

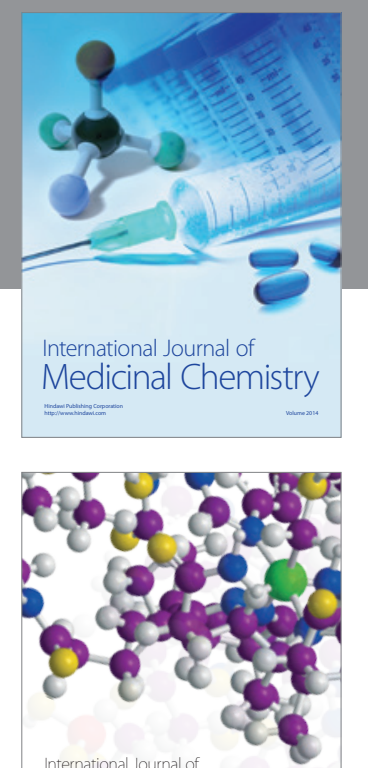

\section{Carbohydrate} Chemistry

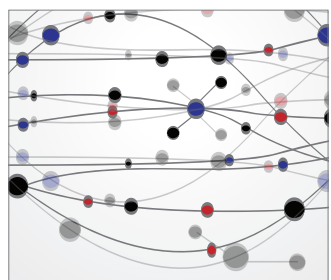

The Scientific World Journal
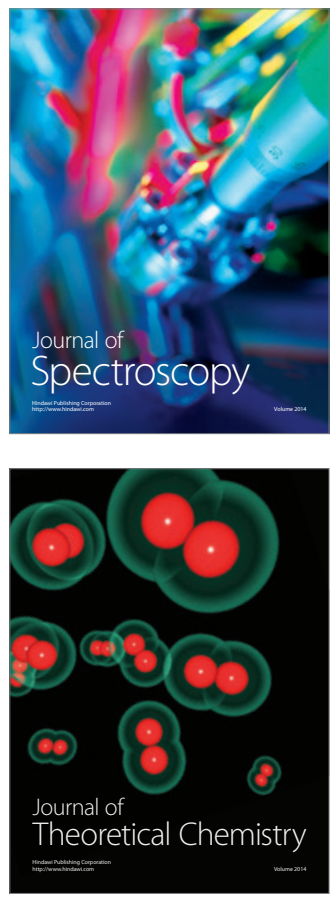
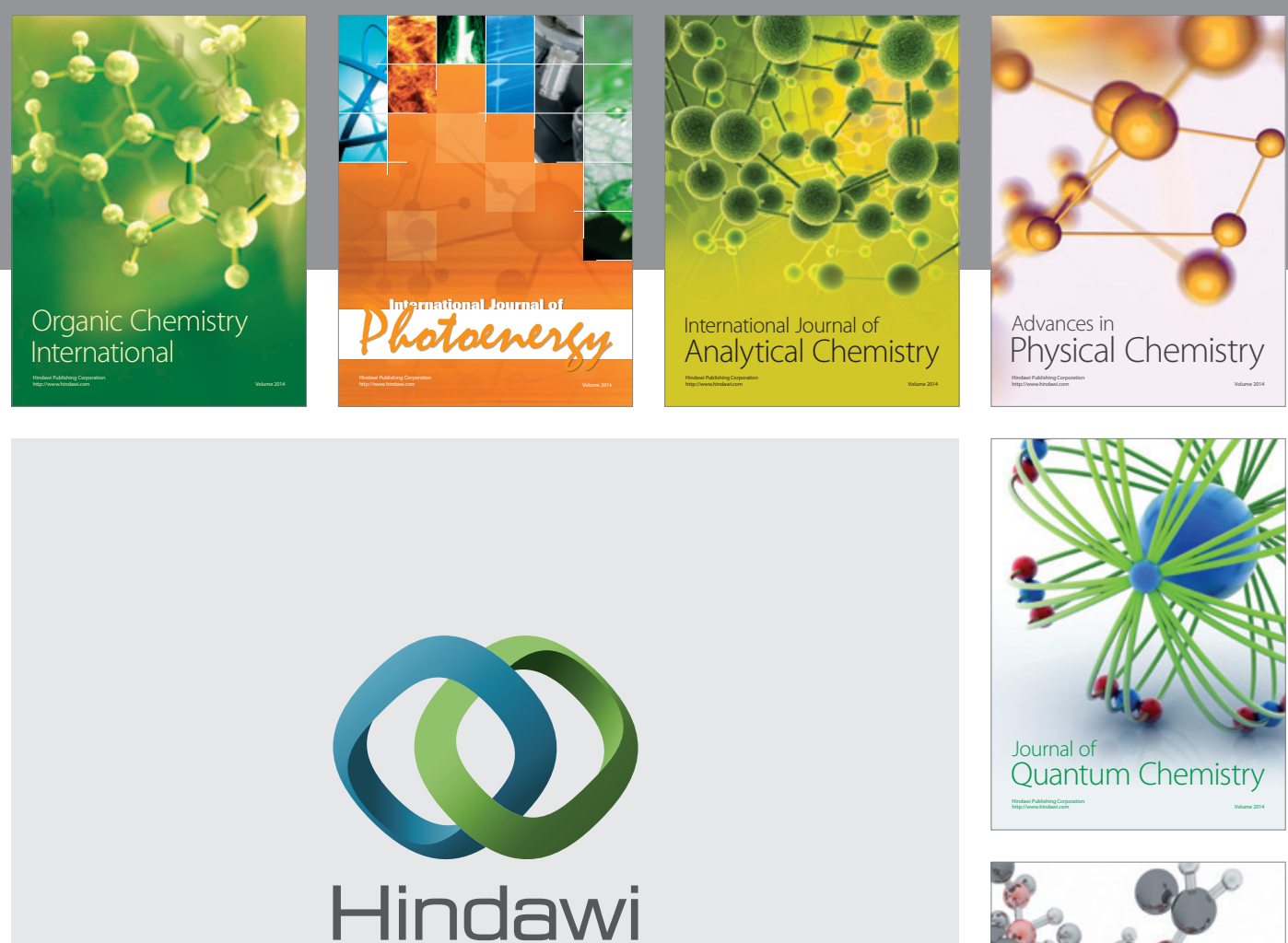

Submit your manuscripts at

http://www.hindawi.com

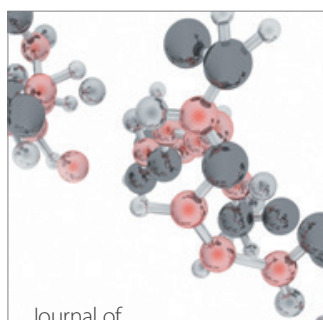

Analytical Methods

in Chemistry

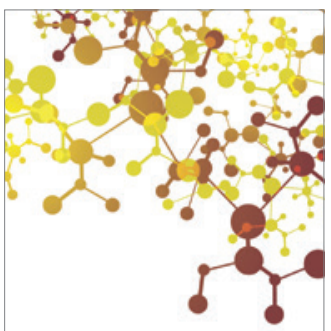

Journal of

Applied Chemistry

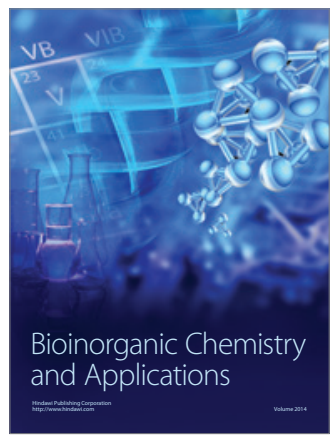

Inorganic Chemistry
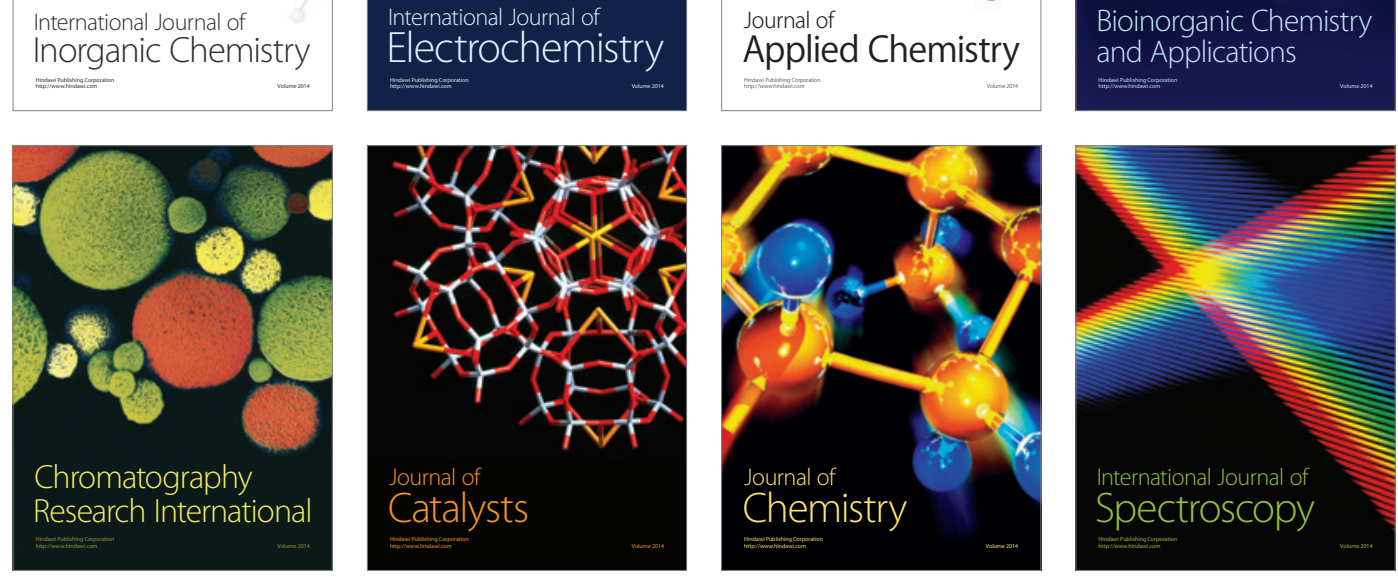